\title{
The Development of Effective Clinical Teaching Model (ECTM) and The Effects to Self Efficacy of Nurse Clinical Instructors in Jakarta State Hospital
}

\author{
Anwar Kurniadi ${ }^{1}$ \\ The Republic of Indonesia Defense University \\ * Correspondent Writer. E-mail: anwarmoker68@gmail.com \\ Ratna Sitorus ${ }^{2}$ \\ Universitas Indonesia \\ E-mail: ratnasit@hotmail.com
}

Agung Waluyo ${ }^{2}$

Universitas Indonesia

E-mail: agungwss@ui.ac.id

Sabarinah Prasetyo ${ }^{2}$

Universitas Indonesia

E-mail: sabarinahprasetyo@gmail.com

\begin{abstract}
Self-efficacy of clinical nurse instructors (CNI's) could improve the socialization of nursing professionals of nursing students, whereas, on the fact that their selfefficacy was still low. The purpose of this study was to know the effect of an effective clinical teaching model on knowledge, attitude, and self-efficacy of CNI's. The second step used a pre-post test with control group design, to know the effects of an effective clinical teaching module (ECTM) by training toward knowledge, attitudes, and self-efficacy. The sampling method used consecutive sampling that included 74 CNI's (37 intervention and 37 control). The research result showed that ECTM training: 1) could improve significantly (P-value $0,00)$, the variable knowledge, attitudes, and self-efficacy; 2) knowledge variable most affected (77\%). The conclusion was the ECTM training significantly improved knowledge, attitudes, and self-efficacy of CNI'S, and knowledge was the most affected variable.
\end{abstract}

Keywords: Effective Clinical Teaching Module (ECTM), Knowledge, Attitudes, Self Efficacy

\section{Introduction.}

Clinical practice was the integral component that influences the success of the nursing program because in the clinical practice the nurse's student enables to improve the knowledge, attitude, clinical skill, or professional nursing socialization (Whittle, 2007). The success of nurse students in clinical practice needs the role of clinical nurse instructors (Kube, 2010). The role of clinical nurse instructors are planning, and teaching, and supervising, and evaluating the performance of nurse's student (Kube, 2010). Whereas the role of clinical nurse instructors (CNIs) depends on competence and self-efficacy (Ali, 2012).

Self-efficacy is defined as a perceived concern with people's belief in their capabilities to mobilize the motivation, cognitive resources, and course of action needed to exercise control over given events (Bandura, 1997). According to Nugent et al., 1999), self-efficacy has two kinds, general teaching self-efficacy that is a strategy to teaching and assess the need of nursing students, 
and personal teaching self-efficacy is a strategy to apply good behaviors and to evaluate nursing students performance.

Self-efficacy is an important factor in clinical learning because it can arise clinical nurse instructors apply good clinical teaching (Mould, 2010). Good clinical teaching creates a positive clinical learning environment (Knox and Mogan, 1985; Whitehead, 1997), or a conducive clinical learning environment (Uukule, 2006). The next beneficial effect is a) reach clinical teaching successfully; b) brave to face a barrier, and performance tool for the outcome, and academic or behaviors); and d) choosing an activity, time, and effort to accomplish tasks promptly and correctly (Bandura, 1997; Ellis et al., 2010).

However, from last research results showed that self-efficacy in the clinical learning environment was attention less by nurse's manager, and it was still on low grade (Nugent et al, 1999). Besides that, nurse clinical instructors still did not have prepared to teach, and making interpersonal relationships less, and evaluation tends to subjective, and personality-less attractive, less to making collaboration and demonstrate nursing intervention, and low self-efficacy (Kurniadi, 2013). The bad condition would be decreasing the credibility of CNIs (Nelson, 2011). So that way, it was needed to develop a new model that can improve the ability of interpersonal relationships, and clinical teaching, and personality performance, professional nursing competition or role model, and good evaluation.

\section{The Purpose}

The purpose of this study was to know the effect of the effective clinical teaching model (ECTM) on the knowledge, attitude, and self-efficacy of nurse clinical instructors (CNIs).

\section{Method}

The research design used quasi-experimental with pre-post test control group design. With sampling method used consecutive sampling that fulfilled inclusion criteria: at least graduation bachelor nurse, experience as nurse clinical instructor 1 year, and ready to conduct until the end of this research (Benner et al., 2010). Finally, the sample selected 38 from the intervention group and 38 from the control group.

This research continued the prior research that was found by Kurniadi, (2013) that known by the effective clinical teaching model (ECTM). ECTM was synthesized from caring Swanson theory (1993), and effective clinical teaching concept of Knox and Mogan (1985), and the effective clinical teaching concept of Whitehead (1997). ECTM had 5 dimensions of clinical teaching, interpersonal relationship (IR), personality (P), teaching ability (TA), role model (RM), and evaluation (E). Based on the five dimensions, this research was conducted.

Two groups are intervention group got training of ECTM in Jakarta Persahabatan general hospital, and the control group did not get training of ECTM in Jakarta Fatmawati general hospital. Monitoring and evaluation was conducted to assess the attendance, participation, knowledge, attitude, and training outcome. On the last day, found $1 \mathrm{CNIs}$ of the intervention group was stated to fail because 2 days absent. So there were $37 \mathrm{CNI}$ passed. Whereas the control group found 1 CNIs out of duty for 3 days. So there were 37 CNIs passed

\section{Results and Discussion}

The ECTM training purposed to identified of the effect on knowledge, attitude, general teaching self-efficacy, and personal teaching self-efficacy variables. The training was one source of self-efficacy to improve self-efficacy CNIs (Nugent et al., 1999). The goal of the 
training was to improve and formed behavior and maintain self-efficacy. Mastering content formed small group (2 people), middle group (8-10 people) collaboration to solve clinical teaching (Bastable, 1999). The training method used a pre-test, lecture, discussion, structural task, role play for 3 days, and simulation to improved the skill of intelligent social, behavior (Bandura, 1997). I gave the training 5 theories, about Swanson caring (1993), traits behavior of The Myers Briggs Type Indicator/MBTI dan The Big Model (Robbins, 2013). The skill of MBKE there is 55 kinds, 11 skills of interpersonal relationship, 11 skills of behavior, 14 skills of teaching ability, 12 skills of role model, 7 skills of evaluation.

ECTM impressed to collaboration and role model of a CNI's, that ease to transfer how to conduct nursing care plan high quality and safety. I purposed this point a nurse was ready to face the globalization era that used universal coverage in Indonesia insurance and the trend of increasing mortality of communicable diseases (like cardiac arrest and stroke and cancer and the diseases of smoke affected) than communicable diseases. If nurses could conduct nursing care plan well and high quality, it could decrease the long stay of the client, so that way can decrease cost hospitalization of client and decrease the workload of provider and benefit to gain revenue of hospital. A good role model could be able to conduct health education effectively so that it could improve and maintain healthy lifeways.

\subsection{Knowledge}

Based on table 1, showed that the highest increase of mean score was on the teaching ability dimension $(9,73)$. Whereas the lowest score was the evaluation dimension(2,14). Based on table 1 showed that knowledge as the item and as a dimension of CNIs in the intervention group was higher than in the control group after ECTM training. The results proved the first minor hypothesis that the mean score of knowledge of the CNIs in the intervention group would be higher than in the control group.

Table 1

Description of Knowledge Dimension before and after ECTM Training on Intervention Group ( $\mathrm{n}=37)$ and Control Group $(\mathrm{n}=37)$

\begin{tabular}{|c|c|c|c|c|c|c|c|}
\hline \multirow{2}{*}{ Knowledge } & \multicolumn{3}{|c|}{ Intervention Group $(\mathrm{n}=37)$} & \multicolumn{3}{|c|}{ Control Group (n=37) } & \multirow{2}{*}{$\frac{\text { First Pvalue }}{\Delta \text { (nd Pvalue })}$} \\
\hline & Pre & Post & $\Delta$ & Pre & Post & $\Delta$ & \\
\hline \multirow{10}{*}{$\begin{array}{ll}\text { 1. Interpersonal relationship (IR) } \\
\text { Mean } \\
\text { 2. Personality (P) } \\
\text { Mean } \\
\text { 3. Teaching ability (TA) } \\
\text { Mean } \\
\text { 4. } \text { Role Model (RM) } \\
\text { Mean } \\
\text { 5. Evaluation (E) } \\
\text { Mean }\end{array}$} & & & & & & & $0,474^{\text {a) }}$ \\
\hline & 3,95 & 7,84 & 3,89 & 3,8 & 4,1 & 0,3 & $0,000^{\text {a) }}$ \\
\hline & & & & & & & $0,160^{\text {a) }}$ \\
\hline & 2,3 & 4,9 & 2,6 & 2,14 & 3,0 & 0,86 & $0,003^{\text {a) }}$ \\
\hline & & & & & & & $0,769^{\text {a) }}$ \\
\hline & 9,73 & 15 & 5,27 & 10,2 & 10,4 & $-0,2$ & $\overline{0,000^{\text {a) }}}$ \\
\hline & & & & & & & $0,789^{\text {a) }}$ \\
\hline & 2,7 & 6,8 & 4,1 & 2,35 & 2,05 & $-0,3$ & $0,000^{\text {a) }}$ \\
\hline & & & & & & & 0,967 a) \\
\hline & 2,14 & 6,7 & 4,56 & 1,9 & 2,6 & 0,7 & $0,000^{\text {a) }}$ \\
\hline
\end{tabular}

a) Independen t-test

The Analysis results showed that CNI's knowledge on intervention group about 5 dimensions of ECTM as the item and as dimension was higher than a control group. Knowledge as item after training that increased was a) improve student's self-confidence. This result was the same as finding that the training contains knowledge, expertise, and attitude, and skill could 
improve the self-confidence of the student (Nugent et al., 1999); b) guide taking clinical decisions. Thi result showed that the method of training like a lecture, discussion, role-play, and simulation could improve taking clinical decisions (Notoatmodjo, 2007); c) mastering a nursing skill. This result was under the graduation of a nurse with their experience were easier to master the nursing skill. And also Bandura stated that with vicarious experience (resource of self-efficacy), a clinical nurse instructor responsible to improve nursing care safely and with high quality.

The lowest mean score was direct to make nursing care plans. The result that mastering nursing care plan must need analytic and intuitive thinking, so it needs to give theoretic and practicable that supported by form document how to make nursing care plan (Ali, 2012). So that way it needs supplementary material and media (Notoatmodjo, 2007). The results of the knowledge dimension showed that all of the dimensions increased. The condition convinced that CNI's cognitive included easy to adopt the change and also showed that training method that applied caring suit to improve the knowledge. The highest score was the ability to teach. The results showed CNIs could conduct the hope of Spouse's five keys in clinical teaching befriending, collaborating, coaching, and reflecting (Murray \& Main, 2005),

But for the personality dimension need to improve. Using proper media like picture and symbol material and audio. And also using depth discussion that emphasized argument and reasoning principles (Reilly \& Obermann, 2002). The impact of ECTM toward knowledge was: a) every increasing 1 unit of ECTM could increasing 19 times of knowledge $(B=19,14)$; b) ECTM influenced $77 \%$ of knowledge(R2 adjusted=0,766), so it included a good category.

Finally, this result proved that the content and method of ECTM suit to improve knowledge of CNI about new concepts 5 dimensions: interpersonal relationship, personality, ability to teach, role model, and evaluation (Knox and Mogan, 1985; Whitehead, 1997). I hoped the next impact to increase the attitude of CNI (Bandura, 1997

\subsection{Attitude}

Based on table 2, showed that mean scores of attitude dimension showed that 5 dimensions significantly increased after ECTM training ( $\mathrm{p}$-value $<0,05)$. The highest mean scores were interpersonal relationship dimension ( $\mathrm{IR}=8,7)$ and personality dimension $(\mathrm{P}=8,7)$. Whereas the lowest mean score after ECTM training was role model dimension $(2,3)$. Based on table 2 showed that attitude as the item and as a dimension of CNIs on the intervention group was higher than in the control group after ECTM training. The results proved the second minor hypothesis that the mean score of the attitude of the CNIs in the intervention group would be higher than in the control group.

The Analysis results showed that CNI's attitude on intervention group about 5 dimensions of ECTM as the item and as dimension was higher than the control group. Attitude as item after training that increased was: a) bolster participation actively. If it is involved, it could be easy to create a positive learning environment (Ellis et al., 2010), and also it eases to make clinical decisions, solve clinical problems, reach the clinical target, and create self-confidence of nurses students (Mould, 2010). The participation learning like discussion, role play, and simulation enables the study to create thoughtful, learning by thinking, and learning by doing; b) dynamic behavior and show neatly dressed. The result showed that CNIs could choose the positive performance that is influenced by the content of ECTM training. The positive performance made someone reached the goal of study efficiently (Reilly and Obermann, 2002). 
Training of ECTM was a transition condition that enable CNIs to teach clinical effectively. Therefore, if CNIs have dynamic behavior, so it suited the method of ECTM to improve a friendly attitude (Robbins, 2013). The ability of CNIs showed neatly dressed, which meant that CNIs could apply to care and also raised other people attracting to follow its attitude or behavior (Swanson, 1993). In this CNI were to be professional modeling (Robbins, 2013); and reflecting study for nurse's students (Murray \& Main, 2005).

But the items that needed to increase were to take care of privacy and show empathy and awareness. This condition must be improved by applying caring behaviors, and empathize with interpersonal relationships, and also use 10 technical therapeutic communication (Murray \& Main, 2005). The contrary finding was from Katz (2010) found that one of effective teaching type was giving emphatic to nurse's students.

Table 2

Description of Attitude Dimension before and after ECTM Training on Intervention Group ( $\mathrm{n}=37)$ and Control Group $(\mathrm{n}=37)$

\begin{tabular}{|c|c|c|c|c|c|c|c|}
\hline \multirow{2}{*}{ Attitude } & \multicolumn{3}{|c|}{ Intervention Group $(\mathrm{n}=37)$} & \multicolumn{3}{|c|}{ Control Group (n=37) } & \multirow{2}{*}{$\begin{array}{l}\text { First } \mathrm{P} \text {-Value } \\
\Delta \text { (nd P-value })\end{array}$} \\
\hline & Pre & Post & $\Delta$ & Pre & Post & $\Delta$ & \\
\hline 1. Interpersonal relationship(IR) & & & & & & & $0,950^{\text {a) }}$ \\
\hline Mean & 48,6 & 57,3 & 8,7 & 48,1 & 47,7 & $-0,4$ & $0,000^{\text {a) }}$ \\
\hline 2. Personality $(\mathrm{P})$ & & & & & & & $0,246^{\text {a) }}$ \\
\hline Mean & 31,1 & 39,8 & 8,7 & 32,9 & 33,2 & 0,3 & $0,000^{\mathrm{a})}$ \\
\hline 3. Teaching Ability (TA) & & & & & & & $0,751^{\text {a) }}$ \\
\hline Mean & 60,4 & 68,0 & 7,6 & 58,8 & 59,4 & 0,6 & $0,000^{\mathrm{a})}$ \\
\hline 4. Role Model (RM) & & & & & & & $0,587^{\text {a) }}$ \\
\hline Mean & 30,5 & 32,8 & 2,3 & 28,2 & 28 & $-0,2$ & $0,128^{\text {a) }}$ \\
\hline 5. Evaluation $(\mathrm{E})$ & & & & & & & 0,522 a) \\
\hline Mean & 35,3 & 41,2 & 5,7 & 33,2 & 35,19 & 1,99 & $0,008^{\text {a) }}$ \\
\hline
\end{tabular}

a) Independen t-test

The results of the attitude dimension showed that 5 dimensions increased. The highest score was the ability to teach and then interpersonal relationships. This condition showed that CNIs enable to comprehend how to make a cooperation with nurse's student that was hoped it could improve the awareness of nurse's student to reach their clinical target (Reilly \& Obermann, 2002). I hoped the increasing of the 5 attitude dimensions to raise attitude. According to Robbins (2013), CNIs had high intelligence and stable emotional stability so that CNIs had high self-efficacy.

This finding was the same as Heshmati et al (2011) that interpersonal relationships and the ability to teach that influenced clinical teaching. But on the contrary, it was not the same as a) Knox \& Mogan (1985) that found nursing competency and ability to teach; b) Whitehead (1997) found evaluation; c) Katz (2010), found ability to teach, role model and interpersonal relationship; d) Kotzabassaki et al. (1997) found interpersonal relationship; ability to teach and evaluation; and found ability to teach.

The impact of ECTM toward attitude were: a) every increasing 1 unit of ECTM could increasing 28 times of attitude $(B=28,34)$; b) ECTM influenced $40 \%$ of attitude (R2 adjusted= 0,399), so it included enough category. These results showed that the method of ECTM training could improve the knowledge of CNI and become length term memory (Woolfolk, 2009). In 
this case, they could prove it from the results of pre and post-test every content that showed an increasing score. We would hope it to happen internalization process that can affect attitude changing. So, the impact of ECTM training proved it could improve the knowledge and attitude of CNI (Reilly and Obermann, 2002). Finally, it hoped it could improve the self-confidence and self-efficacy of CNI (Ali, 2012).

\subsection{Self Efficacy}

Based on table 3, showed that the highest mean scores were the general teaching selfefficacy (GTSE) dimension (17,3) and personal teaching self-efficacy (GTSE) dimension $(10,4)$. Based on table 3 showed that self-efficacy as the item and as a dimension of CNIs in the intervention group was higher than in the control group after ECTM training. The results proved the third minor hypothesis that the mean score of self-efficacy of the CNIs in the intervention group would be higher than on the control group.

Table 7

Description of Self Efficacy Dimension before and after ECTM Training on Intervention Group $(n=37)$ and Control Group $(n=37)$

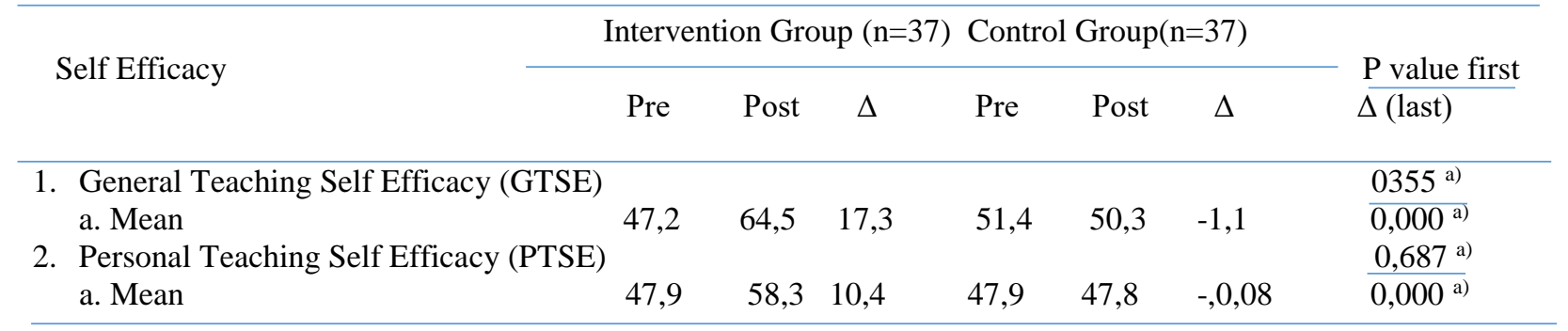

a) Independen t-test

Finally, the knowledge variable was the most affected variable of ECTM training, then attitude, general teaching self-efficacy, and personal teaching self-efficacy variables. The results of multiple linear regression showed that the impact of the ECTM training was an attitude (42\%), knowledge (77\%), general teaching self-efficacy $(74 \%)$, and general teaching self-efficacy $(60 \%)$.

\subsubsection{The Effect of ECTM on General Teaching Self Efficacy}

The results of the analysis showed that general teaching self-efficacy increased significantly. Item of general teaching self-efficacy that influenced was involved nurse staff to teach the nursing student. The impact of staff's involving item was making collaboration among providers so that it could improve self-efficacy of CNIs (Nugent et al., 1999). With the high general teaching self-efficacy, CNIs could prepare to teach and transfer their knowledge and skill to nurse the student and socialize the nursing profession (Whittle, 2007).

The impact of ECTM toward general teaching self-efficacy was: a) every increasing 1 unit of ECTM could increasing 10 times of attitude $(B=10,2)$; b) ECTM influenced $74 \%$ of attitude (R2 adjusted=0,738), so it included good category. The results showed that ECTM training proved to improve general teaching self-efficacy. The lecture used and created a critical thinking process (Bastable et al., 1997). Structural tasks enable to solve clinical problems and taking clinical decisions (Reilly dan Obermann, 2002). Roleplay and simulation enable the 
integration of knowledge, attitude, and psychomotor. So that way enables to create of clinical teaching effectively (Nelson, 2011).

Items of general self-efficacy that needed to improve were emphatic and aware, and take care of privacy. Therefore, the training must be added the capability of CNIs with communication therapeutic that contains 10 technical and have good clinical teaching strategies; and prepared enough time to teach (Nugent et al., 999). ECTM content 10 teaching strategies to teach for CNIs. Here, 10 strategies accustomed CNIs to teach students on problembased learning (Bastable, 1997). Finally, it is accustomed to solving the problem and making clinical decisions. The condition showed that CNIs capable to carry out clinical teaching successfully (Nugent et al., 1999).

\subsubsection{The Effect of ECTM on Personal Teaching Self Efficacy}

The study results showed that the mean score of personal teaching self-efficacy improved. Item of personal teaching self-efficacy like sharing to discuss nursing care plan was the responsible task of CNIs to guide how to make a good clinical decision. Besides that the benefit of sharing was the exchange of good information critically (Bastable, 1997); and also enable to supervise the development of the student. Finally, students are accustomed to thinking critically and scientific reasoning as a motivator to teach promptly (Bandura, 1997).

The impact of ECTM toward general teaching self-efficacy was: a) every increasing 1 unit of ECTM could increasing 7 times of general teaching self-efficacy $(B=6,9)$; b) ECTM influenced $60 \%$ of attitude (R2 adjusted $=0,601$ ), so it included enough category. This result showed that ECTM influenced motivation, personality potential, and intelligence capabilities of CNIs (Schunk \& Pajares, 2002). This finding was the same hope by Bandura (1997) that verbal persuasion promptly could improve their self-efficacy themselves (Nugent et al, 1999). This condition placed CNIs on the level that capable to control their behaviors by restraint their extreme emotions. Besides, that CNIs showed as good role models against nurse students (Murray \& Main, 2005).

Because ECTM training showed the development of general teaching self-efficacy and personal teaching self-efficacy, automatically CNIs created a positive clinical learning environment, so it eases to reach a target of clinical practice especially the nurse profession, and reach successful student outcomes (Ellis et al., 2010). The study results showed that the ECTM module has content and method that suit to improve knowledge and skill to teach practicable (Reilly \& Obermann, 2002).

Finally, ECTM was the dominant variable to improve the attitude of CNIs (28 times) than knowledge (19 times), general teaching self-efficacy ( $B=10$ times), and personal teaching selfefficacy (7 times). So, CNIs have capabilities to change self-efficacy higher than before training. In another word, CNIs could adopt ECTM training through receiving phase of attitude as someone that enables to use knowledge and attitude domain effectively (Notoatmodjo, 2007).

Based on results analysis that the ECTM could increase knowledge (77\%) that attitude (40\%) and GTSE (74\%), and PTSE (60\%). In this matter, CNI's could master new information well and to belong memory (Potter dan Perry, 2005). So that way the ECTM must be corrected by adding time of training and new method that was the practice in clinical teaching directly to nursing students. The ECTM was up to comprehend on same behavior phase and copying behavior phase, but it was not matched dependent behavior yet (Robbins, 2013). 


\section{Conclusion}

The conclusion of this study after training of the ECTM model showed the improvement of CNIs about knowledge, and attitude, and self-efficacy, and variable of knowledge is the most affected by the training.

\section{References}

[1] W hittle, R. 2007. Decisions, Decisions: Factors that Influence Student Selection of Final Year Clinical Placement. Doctor Dissertation submitted to University of Canterbury.The faculty of Education of Canterbury University: by Pro Quest LLC.

[2] Kube, M. L. 2010. The Relationship of Nursing Faculty Clinical Teaching Behaviors to Student Learning. Doctoral dissertation submitted to College of Saint Mary, degree of doctor in education. The faculty of College of Saint Mary: by Pro Quest LLC.

[3] Ali, W.G. 2012. Caring and effective teaching behavior of clinical nursing instructors in clinical areas as perceived by their students. Journal of Education and Practice, Vol 3, No.7.

[4] Bandura, A. 1997. Self-efficacy: The exercise of control. New York: NH Freeman \& Company.

[5] Nugent, E.K., Bradshaw, M.J., and Kito, N. 1999. Teacher self-efficacy in new nurse educators. Journal of Professional Nursing, Vol 15, No 4: 229-237.

[6] Mould, Y. B. 2010. Clinical teachers' and Nursing Students' Empowerment in Acute Care Settings. The School of Graduate and Post-doctoral Studies, The University of Western Ontario Canada.Tesis unpublished.

[7] Knox, J.E., \& Mogan, J. 1987. Characteristics of 'best' and 'worst' clinical teachers as perceived by university nursing faculty and Students. Journal of Advanced Nursing 12, 331-337, Retrieved from http://wordpress.up.edu/clinicalfaculty/files/2013/03/Best-andworst-clinical-teachers.pdf.

[8] Whitehead, D. K. 1997. Characteristics of effective clinical and theory instructors as perceived by $L P N$ to $R N$ versus generic students in an associate degree nursing program. ProQuest ETD Collection for FIU. Paper AAI9726726. Retrieved from http://digitalcommons.fiu.edu/dissertations/AAI9726726.

[9] Uukule, N. 2006. Guidance of student nurses by clinical nurse instructors $i$ a training hospital of Oshana Region. The doctoral dissertation of Master of Nursing Science of The University of Namibia. Retrieved from http://wwwisis.unam.na/theses/uukule2006.pdf\#page=1\&zoom=auto,-99,792.

[10] Ellis, S., Ganzach, Y., Castle, E., \& Sekely, G. (2010). The effect of filmed versus personal after-event reviews on task performance: The mediating and moderating role of selfefficacy. Journal of Applied Psychology, 95, 122-131.

[11] Kurniadi, Anwar. 2013. Preliminary studies about the capabilities of clinical teaching and self-efficacy of clinical nurse instructors di 5 hospitals in Jakarta. Dissertation of Nursing Faculty of Indonesia University. Unpublished.

[12] Nelson, N. 2011. Beginning Nursing Student's Perceptions of The Effective Characteristics and Caring Behaviors of Their Clinical Instructor. Dissertation Doctor of Philosophy, Capella University. Retrieved from http://search.Proquest.Com/dissertation/Docview/861626965/FulltextPDF/4D00D DEB79OA435BPQ/1/account. 
[13] Benner, P., Sutphen, M., Leonard, V., \& Day, L. (2010). Educating nurses. A call for radical transformation. San Francisco CA: Jossey-Bass.

[14] Swanson, K.M. 1993. Nursing as Informed Caring for The well-being of others. Journal of Nursing Scholarship.

[15] Bastable, S. B. 1997. Nurse of Educator: Principles of Teaching and Learning. Boston: Jones \& Bartlett Publisher Inc.

[16] Robbins, S.P., \& Judge, T.A. 2013. Organizational Behavior, Boston: Prentice Hall

[17] Notoatmodjo. 2007. Health promotion and behavioral science. Jakarta: Rineka Cipta.

[18] Murray. C.J. \& Main, A. 2005. Role modeling as a teaching method for student mentors. Nursing Times; 101:26, 30-33.

[19] Reilly, D.E. \& Oberman, M. 2002. Clinical Teaching in Nursing Education. 2nd edition. Jakarta: EGC.

[20] Katz, R.S. (2010). Novice teacher induction: Are teachers receiving the support they need and want? Doctoral dissertation. Retrieved from http://www.mss3.libraries.rutgers.edu/dir/TMP/rutgers-lib_30980-PDF-1pdf.

[21] Heshmati, N.F., \& Vanaki, Z. 2010. Professional approach: the key feature of effective clinical educator in Iran. Nurse Educ Today, 30.163-8. Doi:10.1016/j.nedt.2009.07.010.

[22] Kotzabassaki, S., Panou, M., Dimou, F., Karabagli, A., Koutsopoulou, B., \& Ikonomou, U. 1997. Nursing Students' \& Faculty's Perceptions of the Characteristics of Best ${ }^{\text {ee }}$ and

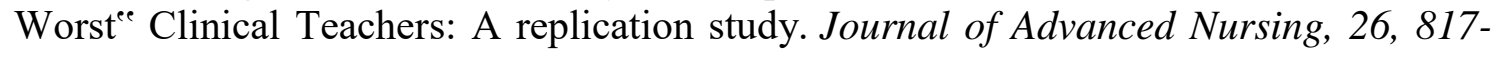
824.

[23] Potter, P.A., \& Perry, A.G. 2009. Fundamental of nursing. (7th ed). Jakarta: EGC. 